\title{
O DESAMPARO E A INVISIBILIDADE DOS REFUGIADOS AMBIENTAIS: ESTUDO À LUZ DO CASO BANGLADESH
}

\section{Douglas Luis Binda Filho', Júlia Chequer Feu Rosa², Letícia Pereira de Lemos ${ }^{3}$, Margareth Vetis Zaganelli ${ }^{4}$}

RECEBIDO: 31/03/2018 | 18/06/2018

DOI: $10.5902 / 2317175831949$

\section{RESUMO}

Este artigo visa analisar a situação dos refugiados oriundos de catástrofes naturais, à luz do caso Bangladesh, considerado um dos países mais afetados pelo aquecimento global. Com esse desígnio, a partir de metodologia exploratória, utilizando pesquisa bibliográfica e documental, o presente trabalho dispõe a respeito do conflito etimológico do termo "refugiado", uma vez que considera-se haver uma exclusão dos refugiados ambientais e, consequentemente, geram-se dificuldades de estabelecer métodos eficazes de proporcionar asilo a esses indivíduos. Visa-se comprovar a complexa conjuntura em que essas pessoas se encontram, uma vez que, ainda que consigam se deslocar para outros territórios, há uma forte presença de xenofobia e uma dificuldade de adaptação dos indivíduos ao destino. Além disso, o estudo visa ressaltar a existência do Projeto de Limoges e a sua importância para a futura criação de dispositivos legais que compreendam o tema em sua especificidade. Conclui-se ainda que, embora não haja dispositivos que auxiliem diretamente no entendimento dos refugiados ambientais, esses indivíduos deslocados são, antes de tudo, titulares de direitos humanos e, portanto, é importante reconhecê-los como detentores dos direitos básicos de todo ser humano.

Palavras-chave: Refugiados ambientais; Caso Bangladesh; Projeto de Limoges; Asilo; Xenofobia.

\footnotetext{
${ }^{1}$ Graduando em Direito pela Universidade Federal do Espírito Santo (UFES). Membro do Grupo de Pesquisa Bioethik (UFES) e do Grupo de Pesquisa Migrare(UFES).

${ }^{2}$ Graduanda em Direito pela Universidade Federal do Espírito Santo (UFES). Membro do Grupo de Pesquisa Bioethik (UFES) e do Grupo de Pesquisa Migrare(UFES).

${ }^{3}$ Graduanda em Direito pela Universidade Federal do Espírito Santo (UFES). Membro do Grupo de Pesquisa Bioethik (UFES) e do Grupo de Pesquisa Migrare(UFES).

${ }^{4}$ Doutora em Direito (UFMG). Mestre em Educação (UFES). Estágios Pós-doutorais na Università degli Studi di Milano-Bicocca (UNIMIB) e na Alma Mater Studiorum Università di Bologna(UNIBO). Professora Titular da Universidade Federal do Espírito Santo (UFES). Docente permanente no Programa de Pós-Graduação em Gestão Pública da Universidade Federal do Espírito Santo (UFES). Coordenadora do Grupo de Pesquisa Bioethik (UFES).
} 
DOUGLAS LUIS BINDA FILHO, JÚLIA CHEQUER FEU ROSA, LETÍCIA PEREIRA DE LEMOS, MARGARETH VETIS ZAGANELLI

\begin{abstract}
This article aims to analyze the situation of refugees from natural disasters - caused by anthropic actions or essentially environmental cause, in the light of Bangladesh, considered one of the most affected countries in the global warming era. With this intent, based on an exploratory methodology, using bibliographical and documentary research, it establishes the etymological conflict of the term "refugee", since it is considered to exist an exclusion of environmental refugees, it arises difficulties to establish effective methods of providing asylum to these individuals. This article intends to explain this situation in order to prove the complex conjuncture of these individuals' lives. Although they can move to other territories, there is a strong presence of xenophobia and a difficulty of adaptation of the individuals to the destination. In addition, the study aims to highlight the existence of the Limoges Project and its importance for the future creation of legal devices that will understand the theme in its specificity. It is also concluded that, although there are no devices that directly aid the understanding of environmental refugees, these displaced individuals are, above all, owners of human rights and therefore it is important to recognize them as holders of the basic rights.
\end{abstract}

Keywords: Environmental refugees; Bangladesh Case; Limoges project; Asylum; Xenophobia.

\title{
1 Introdução
}

Há indícios da existência do fenômeno migratório desde os tempos mais remotos. A fim de sistematizar historicamente esse processo tão presente na sociedade, Douglas Massey (1990) desmembrou-o em quatro períodos: o primeiro, de 1500 a 1800, durante a corrida colonial-mercantilista; o segundo, no início do século XIX, conhecido como o período industrial de imigração; o terceiro, de 1900 a 1915, com a presença da migração internacional de pessoas de países industrializados europeus para as ex-colônias em desenvolvimento; e o quarto, que começou por volta de 1960, tornando a migração um fenômeno global.

$\mathrm{Na}$ atualidade, as migrações internacionais representam o resultado de relações socioeconômicas assimétricas. Em um mundo desigual, inúmeros fatores são responsáveis por instigar a migração e a condição de refugiado a inúmeros indivíduos. O direito internacional estabelece que "refugiado" é o indivíduo fora de seu país de origem por medo de perseguição, conflito, violência ou outras circunstâncias, tornando-se imprescindível a sua "proteção internacional". As situações vividas por essas pessoas tornam-se tão insuportáveis que os indivíduos têm de cruzar as fronteiras de seus países a fim de procurar asilo.

A crise dos refugiados é uma problemática que urge uma discussão profunda. No meio do ano de 2017, o Alto Comissariado das Nações Unidas para Refugiados (ACNUR) revelou que aproximadamente 65,6 milhões de pessoas foram obrigadas a deixar seus países de origem por causas diversas em 2016 (NASCIMENTO, 2017). Essa questão acaba por levar à compreensão de que são necessárias políticas públicas mais eficazes que possam garantir a tutela de tantos indivíduos. 
Ademais, considera-se uma problemática presente a obliteração da inclusão direta da tutela dos refugiados que se deslocam por conta de fatores ambientais. Assim, compreende-se uma dificuldade ainda maior em entregar auxílio e asilo a esses indivíduos. É importante ressaltar, contudo, que existem meios de gerir futuras legislações específicas nacionais e internacionais sobre o tema a partir de documentos-base, como o importante Projeto de Limoges, responsável por compreender a urgência do debate acerca dos refugiados ambientais e da necessidade de formular um dispositivo específico que seja capaz de versar diretamente sobre a questão.

Nessa perspectiva, insere-se Bangladesh, território presente em um acentuado processo migratório, urgindo a sua análise e discussão. Esse processo se dá como reação a desastres e a situações ambientais que tornam insuportável a continuidade da vida dos indivíduos no território. Além disso, há um recebimento igualmente caótico de refugiados que adentram o território, devido a desastres e problemas ambientais em seus países de origem, à perseguição, como os refugiados Rohingya de Myanmar (AGENCIA EFE, 2017), dentre outros fatores.

\section{Fatores que urgem a tutela dos refugiados ambientais}

As catástrofes naturais, em suas múltiplas formas, isto é, tanto por desastres causados devido a ações antrópicas ou por aqueles cuja causa é puramente ambiental, estão cada vez mais presentes como causas de migrações humanas. $O$ relatório do Alto Comissariado das Nações Unidas para Refugiados (ACNUR) de 2017, além de revelar um número extremamente grande de indivíduos deslocados em 2016, gerou atenção para o fato de que, do total forçado a se deslocar, 10,3 milhões de pessoas são novas e cerca de dois terços (6,9 milhões) delas se deslocaram dentro de seus próprios países. Dentre esses, considera-se haver um intenso número de indivíduos que migraram devido às causas ambientais.

Pentinat (2018) atenta para o fato de que as secas e inundações intensas, a poluição, a construção de grandes barragens e muitas outras formas de alteração das condições ambientais são as responsáveis por fazer com que muitas pessoas tenham que migrar devido à impossibilidade de continuar a viver nas áreas afetadas.

En relación a las causas naturales de la degradación ambiental, destacan por su importancia los desastres naturales, que engloban actividades geofísicas (terremotos, erupciones volcánicas, avalanchas, deslizamientos de tierra, etc.), actividades meteorológicas (ciclones tropicales, tornados, huracanes, tifones, etc.) y actividades hidrológicas (inundaciones, por ejemplo). (PENTINAT, 2018, p. 104, tradução nossa)'

\footnotetext{
1 Em relação às causas naturais da degradação ambiental, destaca-se por sua importância, os desastres naturais, que incluem atividades geofísicas (terremotos, erupções vulcânicas, avalanches, deslizamentos de terra, etc.), atividades meteorológicas (ciclones tropicais, tornados, furacões, tufões, etc.) e atividades hidrológicas (inundações, por exemplo).
} 
Dessarte, consegue-se compreender que os desastres naturais, muitas vezes oriundos de atitudes humanas, são responsáveis pelo deslocamento de inúmeros indivíduos, sendo inclusive causa mais influente do que migrações geradas por conflitos e violência. Pentinat (2018), utilizando os dados do Centro de Monitoramento de Deslocamento Internacional, aponta que, em 2015, os desastres ambientais foram responsáveis pelo deslocamento de cerca de 19,2 milhões de pessoas (mais que o dobro do número daqueles gerados por conflitos e violência). Ademais, é importante relembrar que é igualmente causa migratória a construção de grandes obras de infraestrutura (ou "projetos de desenvolvimento").

Diante da ação antrópica que pode ocasionar o aumento na quantidade de desastres naturais de várias níveis, surge a preocupação com a solidariedade entre os países e as consequências que uma Nação pode causar para outras. É nesse sentido, que, diante de um mundo globalizado, com a redução de fronteiras físicas, sendo o meio ambiente direito fundamental do ser humano (como espécie em geral), os refugiados ambientais surgem como problema mundial, a dizer:

Os riscos e perigos atuais diferenciam-se do passado pelo alcance global que possuem, instituindo-se nova dinâmica de percepção e reação diante de situações que já não se adequam, por exemplo, às noções de tempo-espaço, classes sociais e de fronteiras da sociedade industrial - Estados, alianças, blocos e continentes. As ameaças globais são, portanto, supranacionais e independem de divisão em classes ou grupos sociais. (RAMOS, 2011, p.49)

Nesse mesmo sentido, a opinião de Ulrich Beck demonstra como fatores importantes dois conceitos sobre a relação homem e natureza. Primeiramente, vale destacar que os homens em geral possuem uma tendência de agir pensando no presente, com base em suas necessidades imediatas, sem considerar os efeitos de suas ações, destacando-se, o conceito do "efeito bumerangue" em que cedo ou tarde os riscos alcancem quem produziu-os (BECK, 2010, p.2627). Ademais, tomando a segurança como princípio fundamental, surge $o$ fenômeno da "irresponsabilidade organizada", que é quando as instituições e tomadores de decisão, sobre a existência, gravidade, origem dos riscos e dos impactos destrutivos das atividades econômicas e as manobras políticas de isenção de responsabilidade por danos globais, se mantêm em silêncio, recusando o seu papel (BECK apud RAMOS, 2011, p. 51).

Logo, ao considerarmos o papel antropológico nos desastres ambientais e os fatores que fazem ser necessária a tutela dos refugiados ambientais, torna-se válida a exploração do significado do termo.

\section{Definição de Refugiados}

Considerando os cenários de degradação e catástrofes naturais, é espontâneo que existam pessoas que, por tais razões, venham a migrar. Em 
realidade, o homem enfrenta desde o início de sua história problemas com a questão ambiental, podendo ser citados períodos de grandes secas, terremotos e tsunamis. Tal é a relevância desses refugiados no âmbito histórico, que Fischel de Andrade (1996) determina que os primeiros relatos de refugiados ambientais se encontram na Bíblia, na qual existem passagens de fugas forçadas devido a calamidades naturais que causaram fome na população. Inclusive, diante de tais situações calamitosas do meio ambiente, o sofrimento causado diante desses acontecimentos tinha em muitas sociedades viés místico, sendo visto como "vingança divina" ou "castigo". A citar, o trecho do Gênesis, capítulo V, versículos 53 a 57, que dizem:

Assim chegaram ao fim os sete anos de fartura no Egito, 54 e começaram os sete anos de fome, como José tinha predito. Houve fome em todas as terras, mas em todo o Egito havia alimento. 55 Quando todo o Egito começou a sofrer com a fome, o povo clamou ao faraó por comida, e este respondeu a todos os egípcios: "Dirijam-se a José e façam o que ele disser". 56. Quando a fome já se havia espalhado por toda a terra, José mandou abrir os locais de armazenamento e começou a vender trigo aos egípcios, pois a fome se agravava em todo o Egito. $57 \mathrm{E}$ de toda a terra vinha gente ao Egito para comprar trigo de José, porquanto a fome se agravava em toda parte. (Tradução: Nova Versão Internacional, 2000)

No entanto, apesar da presença histórica desse tipo de refugiados, diante do aquecimento global, da poluição, da industrialização e do desmatamento (todos problemas que aumentaram exponencialmente ao longo das últimas décadas), fizeram aumentar a quantidade de deslocados ambientais. Assim, com o aumento da quantidade de pessoas afetadas, cresce a preocupação com a questão diante da necessidade de proteção desses indivíduos. Porém, por conta de uma limitação terminológica que se deu ao termo "refugiado", segundo a Convenção relativa ao Estatuto dos Refugiados de 1951, a assistência social e jurídica a estes indivíduos vê-se dificultada. $O$ art. $1^{\circ}$, no ponto 2 da alínea $A$, de tal Convenção estabelece que somente considerarse-ão refugiados aqueles que se moveram "por motivos de raça, religião, nacionalidade, grupo social ou opiniões políticas".

Mesmo que a proteção aos refugiados tenha sido ampliada no tocante a fronteiras e não mais se restrinja a proteção aos atingidos pela 2a Guerra Mundial, pelo Protocolo Relativo ao Status dos Refugiados de 1967, a definição de refugiado continuou a não abarcar aqueles que saíram de suas moradas habituais por motivações ambientais. Após 17 anos, em 1987, ocorreu o Colóquio que gerou a Declaração de Cartagena, já demonstrando avanços na definição, não fazendo, no entanto, menção expressa ao conceito de "refugiados ambientais", a declaração estabeleceu que: 
a definição ou o conceito de refugiado recomendável para sua utilização na região é o que, além de conter os elementos da Convenção de 1951 e do Protocolo de 1967, considere também como refugiados as pessoas que tenham fugido dos seus países porque a sua vida, segurança ou liberdade tenham sido ameaçadas pela violência generalizada, a agressão estrangeira, os conflitos internos, a violação maciça dos direitos humanos ou outras circunstâncias que tenham perturbado gravemente a ordem pública. (Declaração de Cartagena, 1987)

A tomada de consciência acerca da problemática vem ganhando cada vez mais impulso perante os órgãos internacionais, a exemplo disso o PNUMA (Programa das Nações Unidas para o Meio Ambiente) criou uma definição para tal parcela de refugiados:

Refugiados ambientais são pessoas que foram obrigadas a abandonar temporária ou definitivamente a zona onde tradicionalmente vivem, devido ao visível declínio do ambiente (por razões naturais ou humanas) perturbando a sua existência e/ou a qualidade da mesma de tal maneira que a subsistência dessas pessoas entra em perigo. (PNUMA, 1985)

A ampliação do debate sobre a temática no meio acadêmico também é um indicativo de que a problemática vem sendo observada e a solução sido buscada, exemplo disso Claro (2015) propõe uma definição para o termo:

\footnotetext{
"Refugiados ambientais" são refugiados não convencionais e são migrantes forçados, interna ou internacionalmente, temporária ou permanentemente, em situação de vulnerabilidade e que se veem obrigados a deixar sua morada habitual por motivos ambientais de início rápido ou de início lento, causados por motivos naturais, antropogênicos ou pela combinação de ambos (CLARO, 2015, p. 16)
}

É latente a necessidade de que todos os aspectos ressaltados pela autora no tocante à duração, o que inclui ou não a presença do fator sazonalidade, e à interferência ou não do homem na gênese da problemática, sejam considerados quando a inclusão dos refugiados ambientais for feita nas definições formais desse conceito pelos órgãos internacionais. É ressaltado da mesma maneira, por Claro (2016), a etimologia da palavra "refúgio", que remonta ao termo refugiare, que significa "buscar abrigo ou proteção", e que, portanto, não pode ser exclusivamente utilizada por um tratado internacional, ainda que este seja fundamental quanto ao assunto, de modo a ditar o recorte histórico, político e social do que é um refugiado.

No atual contexto, o ACNUR (Alto Comissariado das Nações Unidas para os Refugiados) sugeriu que fosse oficializado a definição de refugiados ambientais, durante uma conferência em Poznam, na Polônia, com o objetivo 
de ampliar a proteção jurídica às pessoas que vivenciem esta triste situação, por meio da criação de dispositivos legais que tutelem seus direitos. Contudo, nada neste sentido foi oficializado durante a conferência.

Essa dificuldade de consenso por parte dos diversos países do mundo é explicada por Pentinat (2006). Ele salienta que o empecilho é o receio, por parte dos Estados, desse reconhecimento resultar em uma desvalorização do presente estado de proteção aos refugiados, pois migrar por motivações ambientais é excepcional em um contexto em que se admitem mais refugiados por motivações políticas. Outro fator decisivo nesta problemática é a exclusão de caráter material, pois tradicionalmente, pela Convenção de 1951, o refúgio é concedido a indivíduos que se dirigiram a outros países, e, na maioria dos casos de deslocamento por razões ambientais, os indivíduos não chegam a cruzar uma fronteira, permanecendo no mesmo país, mas em diferente região. Ademais, é alegado que caso insira-se os refugiados ambientais na definição formal, aceita pela maioria dos países, haveria um aumento de pessoas deslocadas por esse motivo:

É importante destacar também que este reconhecimento jurídico não deixa de ser interessante para os Estados, que pretendem restringir as leis e regulamentos relacionados ao asilo, ou seja, é de especial interesse para os Estados despolitizar as causas do deslocamento das populações, a fim de revogar a obrigação de providenciar asilo político. A expansão das causas não-políticas da migração expande as possibilidades dos Estados de negar o asilo político. Uma vez que o direito internacional atual não obriga os Estados a fornecer asilo aos deslocados por razões ambientais, os Estados invocam fatores ambientais para excluí-los do asilo. (PENTINAT, 2006, p. 92, tradução nossa)

É de extrema importância salientar que em todos, ou pelo menos a maioria, dos eventos naturais catastróficos sejam eles: ciclones, furacões, desabamentos de morros ou encostas, processos de desertificação, seca, tufões, inundações, aumento do nível dos mares, contaminação de rios dentre outros, a ação antrópica foi decisiva na construção do processo que desencadeou os desastres, e esta postura tem gerado resultados desastrosos para a população de todo o globo, conforme Pinto (2009). Urge, desta maneira, realizar uma conscientização mais incisiva da população mundial para que se mude os hábitos de consumo e postura perante o meio ambiente:

Para Raquel Viana, da Fundação João Pinheiro, em entrevista especial ao ISA, diz que existe certa controvérsia na adoção desse termo [refugiado climático]. Assim, ela adverte sobre a necessidade de se colocar claramente a responsabilidade da ação antrópica desses deslocamentos, tanto devido ao aquecimento global quanto a exclusão das populações mais vulneráveis. "Ao colocar a palavra 'ambiental' nesse termo para deslocamentos forçados há uma impressão de que a natureza é a responsável, o que 
pode eximir os responsáveis políticos e os processos sociais que estão por trás", analisa. (GÁMEZ; GARCIA; SPLENDORE, 2015)

No entanto, apesar de as condições terminológicas não condicionarem uma maior possibilidade de auxílio jurídico à camada de refugiados supracitada, o auxílio dos órgãos internacionais não deixa de ser proporcionado. O Alto Comissariado das Nações Unidas para os Refugiados (ACNUR), prestou auxílio aos atingidos por diversas catástrofes naturais, como por exemplo: "o tsunami no Oceano Índico em 2004, o terremoto que ocorreu no Paquistão em 2005, o Ciclone Nargis que atingiu Mianmar em 2008, o furacão que atingiu o Haiti em 2010 e o tufão Haiyan nas Filipinas em 2013." (ALVES,2018, p.23). Desta maneira, há esperanças para a resolução imediata das necessidades dos refugiados, o que é dificultado quando o caso de auxílio é de médio ou longo prazo.

É possível vislumbrar-se, então, proteção jurídica global não específica (ou seja, de caráter geral) para os "refugiados ambientais" no Direito Internacional dos Direitos Humanos, no Direito Internacional das Migrações, no Direito Internacional dos Refugiados, no Direito Internacional Humanitário, no Direito Internacional do Meio Ambiente, no Direito das Mudanças Climáticas e no Direito dos Desastres Ambientais. Isso significa que, enquanto sujeitos de direito, os "refugiados ambientais" poderão ser protegidos por todas as normas jurídicas devido à sua condição humana, estejam eles em situação de migrantes ou não. (CLARO, 2016, p.217)

É imperioso destacar que, embora os refugiados por motivos ambientais não tenham proteção jurídica voltada para seu corte situacional, eles ainda são titulares de direitos humanos, ou seja, todos têm direito à vida, à saúde, à alimentação, ao abrigo, ao movimento, etc., sendo que os dois últimos são decisivos quando se trata de refugiados.

Há uma questão recorrente no tocante à terminologia utilizada. Inicialmente, "refugiado ambiental" foi utilizado por Lester Brown, em 2016. Após sua utilização, em 1985, foi usado em um relatório do Programa do Meio Ambiente das Nações Unidas Ambiente preparado por El- Hinnawi, professor Centro Nacional de Pesquisa Egípcio e popularizado pela ganhadora do Prêmio Nobel da Paz, Wangari Maathai. Em 1995, o professor Norman Myers fez o uso desse nome. Nesse aspecto, cabe ressaltar que o termo "refugiado ambiental" continua sendo o mais utilizado pela mídia.

Con el tiempo, se produjo una proliferación y polarización terminológica y conceptual, surgiendo términos como migrante ambiental, y otras denominaciones similares, tales como migración forzosa ambiental, migración motivada por el medio ambiente, refugiados climáticos, refugiados del cambio climático, personas desplazadas por el clima, refugiados de los desastres naturales, desplazados ambientales, eco-refugiados, climigrantes y perso- 
nas ecológicamente desplazadas, entre otros tantos ejemplos ${ }^{2}$. (PENTINAT, 2018, p. 113)

No entanto, assim como sugere PENTINAT (2018), as diferenças entre esses termos são menos importantes do que o que eles têm em comum, uma vez que todos sugerem que há uma relação direta ou indireta entre a degradação ambiental e a migração.

\section{A falta de previsões legais específicas para os refugiados ambientais}

Diante das recentes catástrofes e da resistência dos países ao recebimento de refugiados diante da crise dos últimos anos, se tornou preocupante o problema dos deslocamentos e a garantia dos direitos dessas pessoas em estado vulnerável. Situações políticas, econômicas, religiosas e até naturais afetam a qualidade de vida de milhares de pessoas ao redor do mundo, fazendo-as sentirem-se obrigadas a se deslocar em busca de um local adequado para o respeito e desenvolvimento de seus direitos fundamentais. No entanto, entra em xeque nessa situação a receptividade dos demais países que passam a se preocupar com a manutenção de seus próprios cidadãos, muitas vezes quebrando princípios universais reconhecidos a esses refugiados que buscam abrigo nestes locais.

Ficou claro com a migração de pessoas durante a Segunda Guerra Mundial que havia a necessidade de uma proteção especial para essas vítimas que fugiam de locais inóspitos à sua vida e dignidade, dando origem ao Estatuto dos Refugiados de 1951. Importante conquista decorrente das situações históricas do séc. XX, o Estatuto foi e continua sendo um documento fundamental para a tutela dos refugiados no mundo todo, sendo a base fundamental das medidas da ACNUR. Entretanto, notou-se uma mudança nas necessidades humanas das últimas décadas, surgindo questões que antes não eram preocupações, como o meio ambiente.

Direito fundamental de terceira dimensão, baseando-se na fraternidade e solidariedade, o direito ao meio ambiente deve ser garantido universalmente, sendo dever de todos protegê-lo, assim como direito de todos usufruir dele. Infelizmente, vemos que essa garantia não tem sido levada a termo, com desastres ambientais causados pelo próprio homem e também pelo aumento climático, foi notado o aumento da quantidade de migrantes ambientais, havendo, em 2014, cerca de 19,3 milhões de refugiados climáticos no mundo, segundo relatório do Centro de Monitoramento de Deslocados Internos (IDMC).

2 Com o passar do tempo, houve uma proliferação e polarização terminológica e conceitual, emergindo conceitos como de migrantes ambientais e outras denominações similares, tais como migração forçada ambiental, migração motivada pelo meio ambiente, refugiados climáticos, refugiados da mudança climática, pessoas deslocadas pela comunidade. clima, refugiados de desastres naturais, pessoas deslocadas ambientalmente, refugiados ecológicos, "climigrantes" e ecologicamente deslocados, entre muitos outros exemplos. 
Com essa nova necessidade crescente, apesar de o conceito clássico de refugiados do Estatuto de 1951 e da expansão dos mesmos em 1967, percebe-se um conflito entre os documentos legais e a necessidade crescente de resguardo aos direitos fundamentais desses "refugiados" que não são oficialmente reconhecidos pela Convenção. Logo, passaremos a analisar os elementos essenciais do conceito de refugiados, assim como a necessidade de uma atualização legal sobre o assunto diante do Projeto de Limoges.

\subsection{Elementos essenciais da definição de refugiados}

Baseando-se na visão clássica de 1951 sobre refugiados, a ACNUR defende a visão de que os deslocados ambientais não se adequam as definições de refugiados vigentes, ressaltando que os mesmos fogem aos requisitos obrigatórios do status de refugiados, que são: a perseguição ou seu fundado temor, a motivação determinada, o necessário amparo por um outro Estado e a extraterritorialidade (SILVA; REI, 2013, p.109).

Primeiramente, deve-se recordar que o status de refugiado (traduzido erroneamente no Brasil como Estatuto), é um instituto jurídico "que visa designar uma posição pessoal, uma condição (...) Ou seja, o status de uma pessoa pode ser alterado caso o contexto do qual aquele decorre seja modificado" (JUBILUT, 2007, p.43). Por tal motivo, uma pessoa nunca será refugiada por natureza, será por uma convenção do direito, respeitando a certos requisitos teóricos que, como vimos, podem excluir desse status pessoas que vivem em situações iguais aos que possuem tais exigências.

No caso específico da perseguição, apesar de a mesma ser elemento central, esta não é definida oficialmente por nenhum diploma legal, deixando o significado do mesmo extremamente aberto, sendo, porém, adotada na doutrina a ideia de que a perseguição deverá ser causada pelo homem, não contemplando os desastres naturais. Acontece que a única definição disponível dada pela ACNUR em seu "Manual de Procedimentos e Critérios a Aplicar para Determinar a Condição de Refugiado - de acordo com a Convenção de 1951 e o Protocolo de 1967 relativos ao Estatuto dos Refugiados" também não soluciona a questão, deixando o tema em aberto para diversas interpretações ao especificar que "perseguição é qualquer ameaça à vida ou à liberdade, devendo ser auferida tanto por critérios objetivos como por critérios subjetivos". Por tal motivo, adotaremos a seguinte definição de perseguição que poderá, também, levar a inclusão dos refugiados ambientais na perspectiva:

Hathaway defende a posição de que, sempre que violados ou sob ameaça de violação qualquer um dos direitos humanos considerados inderrogáveis pela sociedade internacional, tais como o direito à liberdade de crença, à integridade física e psíquica e à saúde, por exemplo, ou seja, aqueles direitos protegidos pela DUDH de 1948 e pelos Pactos Internacionais de Direitos Humanos de 1966, estará presente a perseguição. (PEREIRA, 2009, p. 72) 
Com essa definição em mente, vemos que com base no artigo 12 do Pacto Internacional de Direitos Econômicos, Sociais e Culturais e no artigo 25 da Declaração Universal de Direitos Humanos, e levando em consideração a interdependência dos direitos fundamentais, sendo necessário respeitar um direito para possibilitar o respeito aos demais, pode ser classificada a situação de desrespeito dos refugiados ambientais como perseguição devido à falta de um nível de vida suficiente em casos de perda de meios de subsistência por circunstâncias independentes da sua vontade, como é o caso dos desastres naturais. De qualquer modo, mesmo que os Refugiados ambientais não sejam enquadrados na perspectiva reduzida de perseguição, os mesmos estão caracterizados no caráter de proteção complementar, em que, baseando-se no princípio basilar do Direito Internacional dos Refugiados do nonrefoulement, esses deslocados não poderiam ter seu direito de proteção negado por outros países. Assim, destaca-se:

O non-refoulement, princípio basilar do Direito Internacional dos Refugiados, está consagrado no artigo 33 da Convenção de 51 que impede o retorno de pessoas a situações em que "a sua vida ou a sua liberdade seja ameaçada". Diante disso, poder-se-ia interpretar que a perseguição genérica do artigo $1^{\circ}$ teria tido seu conteúdo delimitado afim de envolver situações de ameaça a vida, segurança e liberdade. (JUBILUT; MADUREIRA; LEVY, 2018, p. 299-300)

No caso específico do "fundado temor", elemento mais recente da definição de refúgio, discutiu-se o nível de temor que seria necessário para ocasionar o status de refugiado. Foi preciso adotar uma mistura, pela própria visão da ACNUR, da questão subjetiva com o objetivo, de modo que não é suficiente a pessoa ter medo de uma situação de risco, é necessário também uma comprovação fática, respeitando sempre o ônus da prova e o benefício da dúvida de um devido processo legal de que a mesma é passível de ocorrer. A destacar:

A este elemento de temor - que é um estado de espírito e uma
condição subjetiva - é acrescentada a qualificação "com razão".
Isto implica que não é só o estado de espírito da pessoa interessada
que determina a condição de refugiado, mas que esse estado de es-
pírito seja baseado em uma situação objetiva. (ACNUR, 2004, p.19)

Devido à uma tentativa de objetivar quais pessoas estariam aptas para o recebimento do status de refúgio, foram estabelecidas motivações específicas em 1967, estando restrito a exemplos específicos de "raça, religião, nacionalidade, grupo social ou opiniões políticas", excluindo a questão ambiental como motivação válida para o deslocamento. $O$ que se esquece é que uma lista que pretende honrar a dignidade humana deveria ter uma abrangência numerus apertus, com um rol somente exemplificativo, já que, diante de uma violação de direitos humanos não se pode mensurar o valor real da vida ou da dignidade humana diante de um desastre natural. 
Em seguida, faz-se necessário explicar o quesito da necessidade de proteção de um outro Estado e a extraterritorialidade (Alienage). Tecnicamente, pela visão de 1951, o status de refúgio só poderia ser dado aos indivíduos que se encontram fora de seu local de origem/ habitação, não sendo considerados, pela definição, os indivíduos que se deslocam dentro de seu mesmo país. Ou seja, caso a pessoa não ultrapasse as fronteiras de seu país, o mesmo não terá possibilidade de proteção internacional. Este é em realidade, um dos princípios invioláveis do Direito Internacional, não havendo exceções à regra.

No entanto, no caso dos refugiados ambientais entram dois fatores que afetam esse elemento essencial. Em realidade, em decorrência dos próprios desastres naturais, por vezes, as vítimas deverão se locomover por outros países para sair da área de risco, podendo sim, existirem refugiados ambientais internacionais. Ademais, em decorrência do fechamento de fronteiras que vem acontecendo ao redor do mundo, caso se mantivesse essa regra fixa de transposição das fronteiras, os refugiados não seriam abrangidos em sua totalidade, tornando a proteção do Instituto de Refúgio "inútil ou superflua" (JUBILUT, 2007, p.48).

Por último, há ainda um atual movimento da ACNUR de ajuda aos "deslocados internos", que, apesar de não ser considerada uma exceção oficialmente ao princípio da extraterritorialidade, mantêm caráter diferenciado na atuação oficial terminológica do instituto. Nesse sentido, a agência ampliou o sentido estrito de refugiados de 1951, trazendo proteção humanitária às pessoas que oficialmente não atravessaram as fronteiras, como é o caso de grande parte dos casos de deslocados ambientais.

Finalizada a análise desses elementos essenciais, destaca-se que, apesar do não enquadramento perfeito dos refugiados ambientais nessa perspectiva, diante da crise migratória e da tendência ao fechamento de fronteiras, cada vez mais as definições parecem reduzidas com uma enumeração numerus clausus que não necessariamente são suficientes para o cenário atual, já que se mantiveram estáveis desde o Protocolo (CLARO, 2012, f. 66).

Desse modo, considerando que, por vezes, o Estatuto dos Refugiados se mantém ultrapassado diante dos refugiados ambientais, é válido considerar a mudança no pensamento internacional em relação a esses grupos que passam por situações análogas às dos refugiados devidamente reconhecidas. O problema, então, é que dificilmente o Estatuto seria modificado para tornar possível a tutela nesses casos, sendo improvável também a concordância internacional em emendar o documento garantindo proteção para as vítimas de desastres ambientais (RIBEIRO, 2013).

Vemos ainda no texto de Ribeiro, que, na visão de Michel Prieur, um dos líderes do Projeto Limoges, a solução adequada seria a criação de um novo documento que garantisse o respeito aos direitos específicos dos deslocados ambientais. Assim, devido à falta de documentos legais que reconheçam a situação específica dos refugiados ambientais, foi realizada, uma distinta iniciativa acadêmica na Universidade de Limoges na França que tentou 
O DESAMPARO E A INVISIBILIDADE DOS REFUGIADOS AMBIENTAIS: ESTUDO À LUZ DO CASO BANGLADESH

regulamentar a questão dos refugiados ambientais, tema que será tratado a seguir. (RIBEIRO, 2013).

\subsection{A Convenção de Limoges}

Desde o Colóquio internacional "Les réfugiés écologiques", reconhecendo o problema que enfrentam os refugiados ambientais, iniciou-se a formação de um grupo de trabalho em 2007 e a elaboração do Projeto de Convenção relativa ao Estatuto Internacional dos Deslocados Ambientais (ou Projeto de Limoges), que é um importante documento de base para as futuras legislações específicas nacionais e internacionais sobre o assunto.

Vê-se que, apesar de haver proteção mínima aos refugiados ambientais de um ponto de vista humanitário de proteção complementar, a situação dos mesmos se mantêm indeterminada, agravando possíveis violações aos direitos fundamentais dessas vítimas que já se encontram em situação frágil. Diante desse cenário, existem quatro questões principais sobre a gravidade do problema que levaram a realização desse projeto:

Verifica-se, portanto, um descompasso entre a gravidade do problema e a inexistência de respostas claras do direito: i) falta de um instrumento jurídico obrigatório que reconheça e proteja os deslocados ambientais; ii) silêncio do Direito Internacional dos Direitos Humanos; iii) insuficiência ou quase inexistência de um direito de desastres que integre a mobilidade humana; iv) inaplicabilidade do sistema de proteção dos refugiados aos deslocados ambientais. $\mathrm{O}$ "tempo dos deslocamentos ambientais" se acelera enquanto o "tempo do direito" continua seu passo lento na construção de respostas, o que requer a harmonização destes dois "tempos" problema/resposta jurídica. (CAVEDON-CAPDEVILLE; PRIEUR; LAVIEILLE, 2018, p. 204)

Ressalta-se que o projeto foi estimulado por diversas organizações que requisitaram um estatuto internacional sobre as migrações climáticas e ambientais, podendo-se citar inclusive o Parlamento Europeu em 2011, e outras declarações internacionais que enfatizavam essa categoria de pessoas deslocadas, como a Declaração do Rio, Princípio 18 sobre Assistência Ambiental, junho de 1992 e a Agenda 21, Capítulo 12, 12.47.

Visto os motivos que levaram à realização dos projetos, deve ser analisado o conteúdo de direitos do documento. Em geral, foi confirmada uma preocupação universal (como demonstrado pelo uso do termo "Toute personne") que se vale do princípio da solidariedade, da proteção efetiva e da não discriminação, prevendo o respeito aos direitos listados sem quaisquer distinções, como já é de praxe em documentos de direitos humanos internacionais, incluindo o art. 2 da Declaração Universal de Direitos Humanos.

No entanto, apesar da universalidade das prerrogativas de solidariedade, responsabilidade e segurança, foi demonstrada a preocupação com duas 
categorias de titulares de direitos, sendo estes: os direitos das pessoas ameaçadas de deslocamento, previstos no capítulo 3, artigos 9, 10 e 11; e os direitos das pessoas deslocadas, previstos no capítulo 4, artigo 12. (CAVEDON-CAPDEVILLE; PRIEUR; LAVIEILLE, 2018, p. 204). Essa distinção, surge em vista de um método preventivo, em que, dando aos ameaçados de deslocamento os direitos de informação e escolha, incluindo sua recusa, poderão ser evitadas situações forçadas que compliquem não só o contexto dos migrantes com a violação de seus direitos humanos, mas também dos Estados que são partes funcionais dessa questão.

Já no caso das vítimas deslocadas, surge um diferencial dessa proposta, tornando possível o recebimento de um status de deslocado ambiental para qualquer pessoa, família, grupo ou população que se enquadre na definição. Porém, o mesmo aconteceria diante de um procedimento formal, devendo ser feito o pedido do status para a Comissão Nacional de Deslocados Ambientais, havendo um período de 30 dias para a realização do mesmo em que a vítima poderia se manter no país em que requer o status sem ser imputável penalmente.

Diante do questionamento da viabilidade das ideias da Convenção, foi realizado o Projeto CADHOM ("Catástrofes e Direitos Humanos"), no qual ocorreu o teste das determinações de Limoges em 7 países, sendo eles: Argentina, Brasil, Camarões, França, Tunísia, Turquia e Vietnam. Diante da experiência foram editadas 26 recomendações para a realização do projeto, destacando-se a importância de uma solução global que conecte os direitos humanos ao meio ambiente, e a possibilidade de adoção oficial do mesmo, havendo somente problemas diante de legislações internas que poderiam ser solucionados com a disposição dos países. Destaca-se, assim, a recomendação 9 do CADHOM, que diz:

Given the small number of binding international standards for disasters, States should ratify existing international and regional standards, incorporate their provisions into domestic law and make needed adjustments to the legal and institutional frameworks to make them effective.

States should take the necessary measures to contribute to the development and strengthening of international and regional disaster law. They should take initiatives in this area within the international community and support proposals that move towards this direction. (RECOMMENDATIONS OF THE CADHOM PROJECT, 2013) ${ }^{3}$

Visto sobre a viabilidade da aplicação das diretrizes do Projeto Limoges, diante da falta de material legal internacional específico que garanta os direitos fundamentais dos refugiados ambientais diante de suas peculiaridades, iremos analisar, no próximo tópico, com base nessa perspectiva, o caso Bangladesh que se tornou símbolo dos deslocados climáticos devido a locomoção de milhares de pessoas.

3 Considerando o pequeno número de padrões vinculantes internacionais sobre a temática do desastre, os Estados devem ratificar os modelos regionais e internacionais existentes, incorporando as previsões em suas legislações nacionais com os ajustes necessários ao conteúdo legal e institucional dos mesmos para torná-los efetivos. Os Estados devem tomar as medidas necessárias para a contribuição do desenvolvimento e do fortalecimento da lei das legislações nacionais e internacionais sobre desastres. As Nações devem tomar iniciativas nessa área juntamente à comunidade internacional e apoiar as propostas que movam para esta direção. 


\section{Caso Bangladesh}

O continente asiático frequentemente sofre com desastres ambientais e os prejuízos econômicos oriundos desses fenômenos. As condições territoriais do local são responsáveis por potencializar essa conjuntura, devido à vasta massa territorial asiática, repleta de montanhas, zonas sísmicas múltiplas bacias hidrográficas, planícies inundáveis e áreas vulcânicas ativas com alto risco. Além disso, um fator preocupante nesse aspecto é o fato de a densidade populacional nesses territórios estar sempre muito alta, o que dificulta ainda mais o controle da situação, visto que, quando há altas na migração, ela se dá em massa e de forma descontrolada.

Nesse cenário de caóticos processos migratórios, encontra-se Bangladesh, ex-colônia paquistanesa e o oitavo país mais densamente povoado do mundo. Considerado um dos países mais afetados pelo aquecimento global, seu território tende a cada vez mais submergir devido à baixa elevação de sua terra em relação ao nível do mar.

No total, a Ásia foi atingida por 2.778 desastres ao longo do período de 20 anos, com 3,8 bilhões de pessoas afetadas, além de quase 841 mil mortes. Na Ásia, as regiões do Sul, do Leste e do Sudeste foram atingidas com mais freqüência por desastres naturais, registrando 2.481 eventos ou $36 \%$ de todos os desastres registrados em todo o mundo entre 1994 e 2013. (CENTRO DE PESQUISA EM EPIDEMIOLOGIA E DESASTRES (CRED), 2015, p.10, tradução nossa.)

Dados da ReliefWeb, serviço digital especializado do Escritório das Nações Unidas para a Coordenação de Assuntos Humanitários e principal fonte de informações humanitárias sobre crises e desastres globais, revelaram, em 2018, um dossiê explanando a crescente problemática que envolve Bangladesh: as inundações oriundas das chuvas de monções.

Since 11 August 2017, heavy monsoon rains have caused intense flooding across more than one-third of Bangladesh. The Bangladesh Meteorological Department warns that heavy rainfall is expected to continue. As per the analysis by the Ministry of Disaster Management and Relief (MoDMR), the floods may be the worst in the last four decades. Incessant heavy rainfall brought by the monsoon triggered flooding in five divisions, 31 districts, 176 Upazilas and 1,173 Unions. Findings from 72 hours-Needs Assessment were published on 21 August and they indicated that a total of about 6.9 million people (1.54 million households) have been affected by the floods. National authorities have confirmed 114 deaths and 197,416 people are temporarily displaced in 703 community shelters. As a result of the extensive floods, 77,272 houses were destroyed, 524,375 were partially damaged. (ReliefWeb, 2018) ${ }^{4}$

$4 \quad$ Desde 11 de agosto de 2017, as fortes chuvas de monção causaram inundações intensas em mais de um terço do Bangladesh. O Departamento Meteorológico do Bangladesh alerta que chuvas fortes devem continuar. De acordo com a análise do Ministério de Gestão e Desastres em Desastres (MoDMR), as inundações podem ter sido as piores das últimas quatro décadas. Chuvas fortes causadas pela monção provocaram inundações em cinco divisões, 31 distritos, 176 Upazilas e 1.173 Uniões. As descobertas da Avaliação de Necessidades de 72 horas foram publicadas em 21 de agosto e indicaram que um total de cerca de 6,9 milhões 
Além disso, Bangladesh possui uma área com a frequente presença de fenômenos naturais como ciclones. Em 2007, o ciclone Sidr foi responsável pela morte de aproximadamente 10 mil indivíduos. Em 2009, o ciclone Aila deixou 339 mortos. Em 2016, o ciclone Roanu causou a morte de 20 e forçou o deslocamento de 500 mil pessoas. Em 2017, o ciclone Mora obrigou à retirada de 450 mil pessoas. Em reação a esses desastres, surgem movimentos migratórios em massa para Daca, a capital do país, para a Índia, devido à proximidade territorial e para diversas regiões do globo. Outro destino muito comum dos bengali é a Itália, e indo para lá muitas vezes na condição de imigrantes ilegais, eles são mais suscetíveis a ser vítimas do tráfico humano:

Al 25 maggio sono sbarcati in Italia 6.033 migranti del Bangladesh, uno ogni dieci stranieri arrivati (il totale è di 50.595, $+33,7 \%)$. I bengalesi giunti quest'anno sono già i tre quarti di tutti quelli del 2016, pari a 8.131. I voli dalla Turchia per Tripoli sono continui. Ad attenderli, i trafficanti di esseri umanis. (LUDOVICO, 2017)

Marco Ludovico (2017) atenta, da mesma maneira, ao fato de que em 2016 os imigrantes bengalis ocupavam o nono lugar no ranking de países que mais mandaram imigrantes para a Itália, passando a ocupar, no ano posterior, o segundo lugar na lista, sendo somente superados pelos nigerianos.

O amparo legal à imigração de tal parcela de refugiados pode ser legitimada pela Constituição de Bangladesh, que estabelece que todos são livres para imigrar e retornar ao país posteriormente

36. Subject to any reasonable restrictions imposed by law in the public interest, every citizen shall have the right to move freely throughout Bangladesh, to reside and settle in any place therein and to leave and re-enter Bangladesh ${ }^{6}$. (THE CONSTITUTION OF THE PEOPLE'S REPUBLIC OF BANGLADESH, 1972.)

Observa-se que há a previsão legal para que se dê o processo de migração. Porém, falta, por parte do governo, dos países que recebem os refugiados e dos órgãos internacionais de proteção ao refugiado, o devido diálogo e consenso para que se chegue a uma decisão que resolva por fim a situação destes que há tanto sofrem com as catástrofes naturais. Isso, de modo a garantir os direitos destes que antes de tudo e qualquer situação são seres humanos, titulares de direitos básicos para que vivam com o mínimo de qualidade e dignidade.

de pessoas (1,54 milhão de domicílios) foram afetados pelas enchentes. Autoridades nacionais confirmaram 114 mortes e 197.416 pessoas estão temporariamente deslocadas em 703 abrigos comunitários. Como resultado das inundações extensas, 77.272 casas foram destruídas, 524.375 foram parcialmente danificadas. $5 \mathrm{Em} 25$ de maio, 6.033 migrantes de Bangladesh foram desembarcados na Itália, um para cada dez estrangeiros chegados (o total é de $50.595,+33,7 \%$ ). Os bengalis chegaram este ano já são três quartos de todos os de 2016, o equivalente a 8.131. Voos da Turquia para Tripoli são contínuos. Esperando por eles, os traficantes de seres humanos.

6 36. Sujeito a quaisquer restrições razoáveis impostas por lei no interesse público, todos os cidadãos terão o direito de circular livremente por todo o Bangladesh, de residir e instalar-se em qualquer lugar e de sair e reentrar no Bangladesh. 
No mundo contemporâneo, vê-se ainda um fluxo migratório corrente de outros países para Bangladesh, como o movimento dos Rohingyas, uma minoria mulçumana extremamente perseguida no território de Mianmar. Somente de agosto a setembro de 2017, aproximadamente 125 mil indivíduos rohingyas buscaram refúgio em Bangladesh segundo a ONU, causando ainda maior superpopulação no território e gerando uma urgência ainda maior na discussão dessa intempérie a fim de estabelecer meios eficazes de controle e formas mais humanas de tutelar a vida desses indivíduos.

\section{Conclusão}

Diante do exposto, é possível evidenciar que os eventos de que Bangladesh e sua população sofrem são de responsabilidade mundial, uma vez que são produtos diretos do aquecimento global, como problema internacional que afeta a todos, mas que se agrava em uma região já propícia a desastres naturais em razão de sua estrutura e localização geográfica no continente asiático. O país é sazonalmente palco de chuvas de monções, sempre muito devastadoras. Considerando que o poderio aquisitivo desta população não é muito elevado e que geralmente suas moradas são palafitas frágeis, feitas principalmente de madeira, é possível imaginar o cenário desastroso a que essa população é exposta anualmente.

A dificuldade de resolver a problemática vivida por essas pessoas é agravada por uma confusão etimológica do vocábulo "refugiado". $\mathrm{Na}$ descrição dos tratados internacionais positivados e ratificados pela maioria dos países do globo, não são abarcados os refugiados ambientais. Uma série de justificativas já foram dadas para isso, no entanto, é preciso reconhecer que antes de se pensar sobre por que não ajudar estes seres humanos deve-se prestar auxílio a estes que, antes de tudo, são seres humanos, que merecem o mínimo de dignidade para viver.

Embora o atual quadro pareça trágico, ainda há esperança para a resolução dessa problemática, e em verdade, esta se mostra cada vez mais próxima de se concretizar. Alguns dos exemplos são a maior atenção da mídia ao tema, o crescimento da produção de documentos nesse sentido, sendo exemplo disso o Projeto Limoges, vanguarda no assunto. Assim, é dever de toda a comunidade internacional lutar pelo reconhecimento e auxílio desses indivíduos e, ademais, promover cada vez mais o debate quanto aos hábitos de consumo e a postura quanto ao meio ambiente, visando a promoção do desenvolvimento sustentável e a diminuição do impacto na biosfera e, consequentemente, as catástrofes naturais. 


\section{Referências}

AGENCIA EFE. Daca, 30 maio 2017. Disponível em: <https://www.efe.com/efe/brasil/mundo/ciclone-mora-tocaterra-em-bangladesh-enquanto-se-mantem-alerta-maximo/50000243-3281669>. Acesso em: 24 dez. 2017.

AGENCIA EFE. Daca, 26 out. 2017. Disponível em: <https://www.efe.com/efe/brasil/sociedade/bangladesh-proibecasamento-entre-rohingyas-e-cidad-os-locais/50000246-3419311>. Acesso em: 24 dez. 2017.

ALVES, Angela Limongi Alvarenga. Refúgio e Soberania Estatal: "Refugiados Ambientais": Angela Limongi Alvarenga Alves. In: JUBILUT, Liliana Lyra et al (Org.). "Refugiados Ambientais". Boa Vista: Editora Ufrr, 2018. p. 16-41. Disponível em: <https://ufrr.br/editora/index.php/editais?download=401:refugiados-ambientais>. Acesso em: 18 mar. 2018

ANDRADE, José H. Fischel de. Direito internacional dos refugiados: evolução histórica (1921-1952). Rio de Janeiro: Renovar, 1996, p. 8-9

BECK, Ulrich. Sociedade de risco: rumo a uma outra modernidade. Tradução de Sebastião Nascimento. São Paulo: Editora 34, 2010, p. 26-27. O efeito bumerangue mostra que não há imunidade em relação aos riscos e que seus efeitos não ocorrem isoladamente, o que faz com que, globalmente, todos tenham de arcar com os ônus.

CAVEDON-CAPDEVILLE, Fernanda de Salles; PRIEUR, Michel; LAVIEILLE, Jean-Marc. O Projeto de Convenção de Limoges sobre o Estatuto Internacional dos Deslocados Ambientais. In: JUBILUT, Liliana Lyra et al (Org.). “Refugiados Ambientais". Boa Vista: Editora Ufrr, 2018. p. 16-41. Disponível em: <https://ufrr.br/ editora/index.php/editais?download=401:refugiados-ambientais>. Acesso em: 18 mar. 2018.

CENTRO DE PESQUISA EM EPIDEMIOLOGIA E DESASTRES (CRED) (Bélgica). HUMAN COST OF NATURAL DISASTERS 2015: A global perspective. Bruxelas: Cred, 2015. Tradução nossa. 24 dez. 2017

CLARO, Carolina de Abreu Batista. A Proteção dos "Refugiados Ambientais" no Direito Internacional. Rev. Interdiscip. Mobil. Hum., Remhu, Brasília, v. 24, n. 47, p.215-218, ago. 2016. Disponível em: <http:// www.scielo.br/pdf/remhu/v24n47/1980-8585-REMHU-24-47-215.pdf>. Acesso em: 18 mar. 2018.

CLARO, Carolina de Abreu Batista. A PROTEÇÃO DOS “REFUGIADOS AMBIENTAIS" NO DIREITO INTERNACIONAL. 2015. 328 f. Tese (Doutorado) - Curso de Direito, Universidade de São Paulo, São Paulo, 2015. Disponível em: <http://www.teses.usp.br/teses/disponiveis/2/2135/tde-08042016-155605/ptbr.php>. Acesso em: 18 mar. 2018.

Escritório do Coordenador Residente da ONU Bangladesh. Bangladesh: HCTT Response Plan - Monsoon Floods (August 2017-January 2018). Disponível em: <https://reliefweb.int/sites/reliefweb.int/files/resources/ Bangladesh_RP_MonsoonFlood_010917.pdf>. Acesso em: 25 mar. 2018.

GÁMEZ, Luna; GARCIA, Carlos; SPLENDORE, Juliana. Cresce o número de refugiados no mundo em função do clima. 2015. Disponível em: <https://www.socioambiental.org/pt-br/noticias-socioambientais/cresce-o-numerode-refugiados-no-mundo-em-funcao-do-clima>. Acesso em: 25 mar. 2018

GARCIA, Evelin Naiara; GONÇALVES, Allyson Julio. Refugiados ambientais: um desafio internacional. Revista Jus Navigandi, ISSN 1518-4862, Teresina, ano 14, n. 2374, 31 dez. 2009. Disponível em: <https://jus.com.br/ artigos/14128>. Acesso em: 25 mar. 2018

JUBILUT, Liliana Lyra. O Direito internacional dos refugiados e sua aplicação no ordenamento jurídico brasileiro / Liliana Lyra Jubilut. - São Paulo: Método, 2007. 240p.

ONU. Declaração no 1, de 1987. Declaração de Cartagena. Cartagena das Índias , 22 nov. 1984. p. 1-5. Disponível em: <http://www.acnur.org/fileadmin/scripts/doc.php?file=fileadmin/Documentos/portugues/BD_Legal/ Instrumentos_Internacionais/Declaracao_de_Cartagena>. Acesso em: 18 mar. 2018.

ONU. Estatuto $n^{\circ}$ 1, de 1951. Convenção Relativa Ao Estatuto dos Refugiados (1951). Genebra, 28 jul. 1951. p. 1-21. Disponível em: <http://www.acnur.org/t3/fileadmin/Documentos/portugues/BDL/Convencao_ relativa_ao_Estatuto_dos_Refugiados.pdf?view=1>. Acesso em: 18 fev. 2018.

PENTINAT, Susana Borràs. REFUGIADOS AMBIENTALES: EL NUEVO DESAFíO DEL DERECHO INTERNACIONAL DEL MEDIO AMBIENTE. Revista de Derecho, Barranquilla, v. , n. 2, p.85-108, dez. 2009. Disponível em: <http://www.scielo.cl/pdf/revider/v19n2/art04.pdf>. Acesso em: 19 nov. 2017. Tradução nossa. 
O DESAMPARO E A INVISIBILIDADE DOS REFUGIADOS AMBIENTAIS: ESTUDO À LUZ DO CASO BANGLADESH

LUDOVICO, Marco. Le nuove rotte dei migranti: dal Bangladesh in Turchia e Libia, poi il gommone per I'Italia. 2017. Disponível em: <http://www.ilsole24ore.com/art/notizie/2017-05-27/bangladesh-turchialibia-poi-gommone-I-italia--225802.shtml?uuid=AEa2uNUB\&refresh_ce=1>. Acesso em: 26 mar. 2018.

MASSEY, Douglas S.. Patterns and Processes of International Migration in the 21st Century. In: CONFERENCE ON AFRICAN MIGRATION IN COMPARATIVE PERSPECTIVE, 1., 2003, Joanesburgo, África do Sul. Patterns and Processes of International Migration in the 21st Century. Joanesburgo, África do Sul: University Of Pennsylvania, 2003. p. 1 - 3. Disponível em: <http://citeseerx.ist.psu.edu/viewdoc/ download?doi=10.1.1.473.925\&rep=rep1\&type=pdf>. Acesso em: 24 dez. 2017. Tradução nossa.

NASCIMENTO, Luciano. Acnur: cerca de 65,6 milhões de pessoas foram forçadas a se deslocar em 2016. Disponível em: <http://agenciabrasil.ebc.com.br/internacional/noticia/2017-06/acnur-cerca-de-656milhoes-de-pessoas-foram-forcadas-se-deslocar-em>. Acesso em: 24 dez. 2017.

PEREIRA, Luciana Diniz Durães. O DIREITO INTERNACIONAL DOS REFUGIADOS: ANÁLISE CRÍTICA DO CONCEITO "REFUGIADO AMBIENTAL". 2009. 172 f. Dissertação (Mestrado) - Curso de Direito, Pontifícia Universidade CatÓlica de Minas Gerais, Belo Horizonte, 2009.

PINTO, Anne Fernanda Rocha da Silva. Refugiados ambientais. In: Âmbito Jurídico, Rio Grande, XII, n. 71, dez 2009. Disponível em: <http://www.ambito-juridico.com.br/site/index.php?n_link=revista_artigos_leitura\&artigo_ $\mathrm{id}=6845>$. Acesso em: 15 nov. 2017.

RAMOS, Érika Pires. REFUGIADOS AMBIENTAIS: EM BUSCA DE RECONHECIMENTO PELO DIREITO INTERNACIONAL. 2011. 150 f. Tese (Doutorado) - Curso de Direito, Universidade de São Paulo, São Paulo, 2011. Disponível em: <http://www.acnur.org/t3/fileadmin/Documentos/portugues/eventos/Refugiados_ Ambientais.pdf?view=1>. Acesso em: 22 mar. 2018.

SILVA, José Carlos Loureiro da; REI, Fernando. INVISÍVEIS: A REJEIÇÃO AO ESTATUTO DO REFUGIADO AMBIENTAL. Leopoldianum, Santos, v. 107, p.105-122, 2013. Disponível em: <http://periodicos.unisantos.br/ leopoldianum/article/view/476/437>. Acesso em: 23 mar. 2018. 